\title{
The formerly fat physician
}

$\mathrm{W}$

hen facing an obese patient, it's tempting to explain the mathematics: they need to eat less and exercise more. True though this is, it's hardly helpful. I too want to tell these patients to put down their venti mochas and pick up their gym clothes, but I try to remember that this advice wasn't helpful for me and is unlikely to be helpful for my obese patients. You see, for all of my remembered life, from the time I was six until two years ago, I was really, really fat. Now I'm not.

Looking back at family photos, something big happened to my family when I was becoming school age. We grew. Well, the kids grew vertically, but the whole family grew horizontally. I more than anyone else. In elementary school, I was "Ben, Ben the big fat hen." By high school, I was approaching 300 pounds.

After high school, I studied singing, where it was not unusual to be fat. I was still on the higher end of the scale, mind you. Later, I worked as a political aid in the dying days of the British Columbia New Democratic Party (NDP) government. In politics, appearances matter, and though overweight males were the norm, my obesity was over the top.

In 2001, the NDP was reduced to two seats in the legislature, and my smoking had increased to two packs a day. After I quit smoking, my weight increased further still. When I later returned to school, taking night classes at a community college while working during the day, I never seemed to find time for a healthy lifestyle. Eventually, I was accepted into medical school where it was anything but normal to be fat.

Even before medical school, I knew a lot about diet. I had had private sessions with dietitians, had tried Weight Watchers, and knew Atkins inside and out. I was great at losing weight: I lost 30 pounds on a low-fat diet, and gained

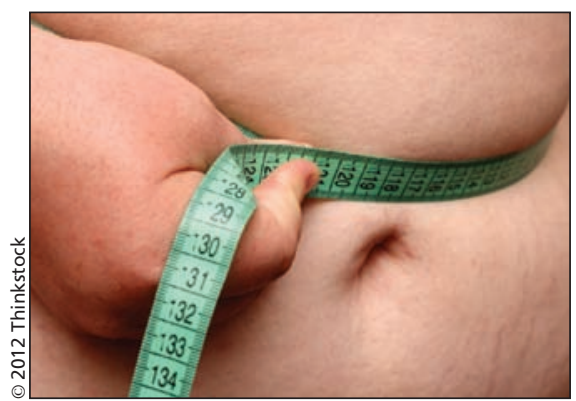

40 back. I lost 50 pounds on a low-carb diet, and gained 55 back. Losing weight was the easy part, keeping it off was the challenge. Oh, and I exercised a lot too; I just ate a lot more.

Back to medical school. My classmates were all very supportive of my weight-loss efforts, and no one ever said a bad word about my weight, but it still came up every day:

Cardiology: Obesity correlates with hypertension and dyslipidemia (I already had both).

Endocrinology: Increased adipose tissue leads to insulin resistance (my fasting glucose was 6.2).

Rheumatology: As our population enlarges so too does the burden of osteoarthritis.

Respirology, nephrology, urology, gynecology (less of a concern for me) ...

The extent of my obesity was well covered: I bought expensive clothes, knew which hospitals had XXX-large scrubs, and used humour to laugh at my largeness. But I was still fat, and it sucked.

During clerkship, my surgery preceptor tried to convince me that surgery held more promise than medicine: to cut is to cure. He told me that he could cure diabetes. I thought he was talking about islet cell transplants, but it turned out that he was a bariatric surgeon.

Two months later, I called the surgeon and asked if he would see me about weight-loss surgery. There was a bit of a wait, and there were some hoops to jump through, but my time came. On May 26, 2010, I graduated from medical school. On the 27th, I had a sleeve gastrectomy, a type of restrictive weight-loss surgery.

It's now 20 months later. I've lost 110 pounds and hope to still shed. I feel healthy, people tell me that I look good, and I can still beat my kids in a race. Last year, I learned to run, something my joints once disapproved of strongly. This year, I've taken up skiing, a sport which seemed unwise at 320 pounds, but is just plain fun at 210 .

Like my colleagues, I tell my patients that they need to exercise more, eat less, and lose some pounds, but I know that many will fail and will continue to need my support and encouragement. Some see fat people as lazy: I was ambitious and hardworking enough to hold a fairly senior position in government at age 22 and to later be accepted into medical school. Others are more charitable and think that fat patients are ignorant: I stayed fat despite learning all about obesity in medical school. I was fat because I ate too much, and my surgeon helped me do what I had been unable to do on my own.

Some patients do need a reminder that their weight is increasing because they take in more than they put out; others need us to reach a little further into the anti-obesity toolbox.

\section{Ben Williams MD}

Second-year family medicine resident University of British Columbia

Nanaimo, BC

Competing interests: Ben Williams received an honorarium from Rogers Information for information he provided for a weight-loss surgery supplement.

\section{CMAJ 2012. DOI:10.1503/cmaj.120251}

Do you have an opinion about this article? Post your views at www.cmaj.ca. Potential Salon contributors are welcome to send a query to salon@cmaj.ca. 